\title{
A Randomized Control Trial Comparing Direct Stripping and Bipolar Electrocoagulation for Laparoscopic Endometriotic Cystectomy-Surgical and Histopathological Aspects
}

\author{
Kallol Kumar Roy, Shilpa Singla, Hemapriya Chawla, Jinee Baruah, \\ Jai Bhagwan Sharma, Sunesh Jain \\ India Institute of Medical Sciences, New Delhi, India. \\ Email: \{drkkroy2003, hemapriya, drkkroy2003, kumar.sunesh\}@yahoo.co.in; \{shilpasingla1,jbsharma2000\}@gmail.com
}

Received August $14^{\text {th }}, 2010$; revised January $16^{\text {th }}, 2011$; accepted January $24^{\text {th }}, 2011$.

\begin{abstract}
The present study compared two different techniques of endometriotic cystectomy at the hilus: continuation of stripping and bipolar elctrocoagulation and cuttin. This was a randomized controlled study was done on 64 patients, who had laparoscopically confirmed endometriomas $>3 \mathrm{~cm}$ in diameter. Endometriotic cystectomy was initiated by excision of a circular rim of tissue at the original adhesion site followed by stripping and randomization was done at the ovarian hilum into 2 groups. In Group I surgery was completed by continuation of stripping and in group II surgery was completed by bipolar coagulation and cutting with scissors. Operative time and operative difficulty were evaluated at both steps by the same surgeon. Histopathology confirmation of the loss of normal ovarian tissue was recorded in the excised cyst and at the hilus separately. Data was analysed using Stata software, fisher's exact test was employed to assess operative difficulty and Kruskal-Wallis test was used to evaluate ovarian tissue quality. The mean operating time was reported to be significantly lesser in the coagulation and cutting group. The operative difficulty was comparable in two groups. The number of primordial follicles sacrificed showed no significant difference in both groups. Complication rate in terms of hemorrhage was higher in the direct stripping group.
\end{abstract}

Keywords: Endometriosis, Laparoscopic Cystectomy, Stripping, Operative Time

\section{Introduction}

Endometriosis occurs in $21 \%-65 \%$ of women being evaluated for infertility [1] and approximately $30 \%-40 \%$ women with endometriosis develop endometrioma [2]. Laparoscopy is the gold standard for the diagnosis and treatment of endometriosis. Several techniques have been described, for the management of ovarian endometriomas. Both laparoscopic techniques (excision and ablation) for the treatment of superficial peritoneal endometriosis are equally effective [3]. For the treatment of ovarian endometriomas larger than $3 \mathrm{~cm}$, laparoscopic cystectomy is superior to drainage and coagulation as it is associated with good conception rates, pain relief and lower recurrence rates [2-4]. It was also associated with a subsequent increased spontaneous pregnancy rate in women who had documented prior sub-fertility (OR 5.21 CI 2.04 -13.29) [5]. However it may lead to inadvertent ex- cision of normal ovarian tissue and decreased ovarian reserve. Infact, an increase in premature ovarian failure rate was reported when both the ovaries are involved in surgery [6].

Various surgical techniques have been described to avoid inadvertent removal of ovarian tissue, and to prevent the future reduction of ovarian reserve [7,8]. However, there is lack of studies in literature comparing technical aspects of surgery from the surgeon's point of view. Present study aimed at comparing two different surgical techniques of endometriotic cystectomy-continuation of stripping vs. bipolar coagulation and cutting at the ovarian hilum with respect to surgical and histopathological aspects. The findings from this study could aid the surgeon in the choice of surgical cystectomy techniques.

\section{Materials and Methods}

This study is a prospective, single blind, randomized 
controlled study carried out at the Department of Obstetrics and Gynecology at All India Institute of Medical Sciences, New Delhi, India, between June 2006 to June 2009. Approval was obtained from Institutional review board (IRB) and informed written consent was taken from all participants before commencement of surgical trial.

A total of 100 women in the age group of 15 - 40 years were assessed for eligibility criteria using clinical and sonographic parameters. Women with clinical and imaging features suggestive of unilateral endometrioma more than $3 \mathrm{~cm}$ were decided to be enrolled. Flow of participants through the study is shown in Figue 1. Patients who had a past history of tuberculosis, previous ovarian cystectomy, severely distorted pelvic anatomy, presence of bilateral endometriomas at surgery or those who required conversion to laparotomy were excluded from the study. Women were recruited into the study only after final laparoscopic confirmation of the unilateral endometrioma.

When approaching the ovarian hilus, a randomization was done using a computer generated random number table. Randomisation was revealed to the surgeon after cystectomy procedure had reached ovarian hilum. Group I consisted of women who underwent completion of the stripping procedure up to complete removal of the cyst wall. The second group or Group II comprised of women who underwent bipolar coagulation of the final cyst wall pedicle, and subsequent cutting with scissors.

Total operative time was recorded in each group from making skin incision to final placement of skin suture. The operative difficulty was assessed by the same surgeon, using three criteria: presence of dense or flimsy adhesions, ability to completely remove of the cyst wall,

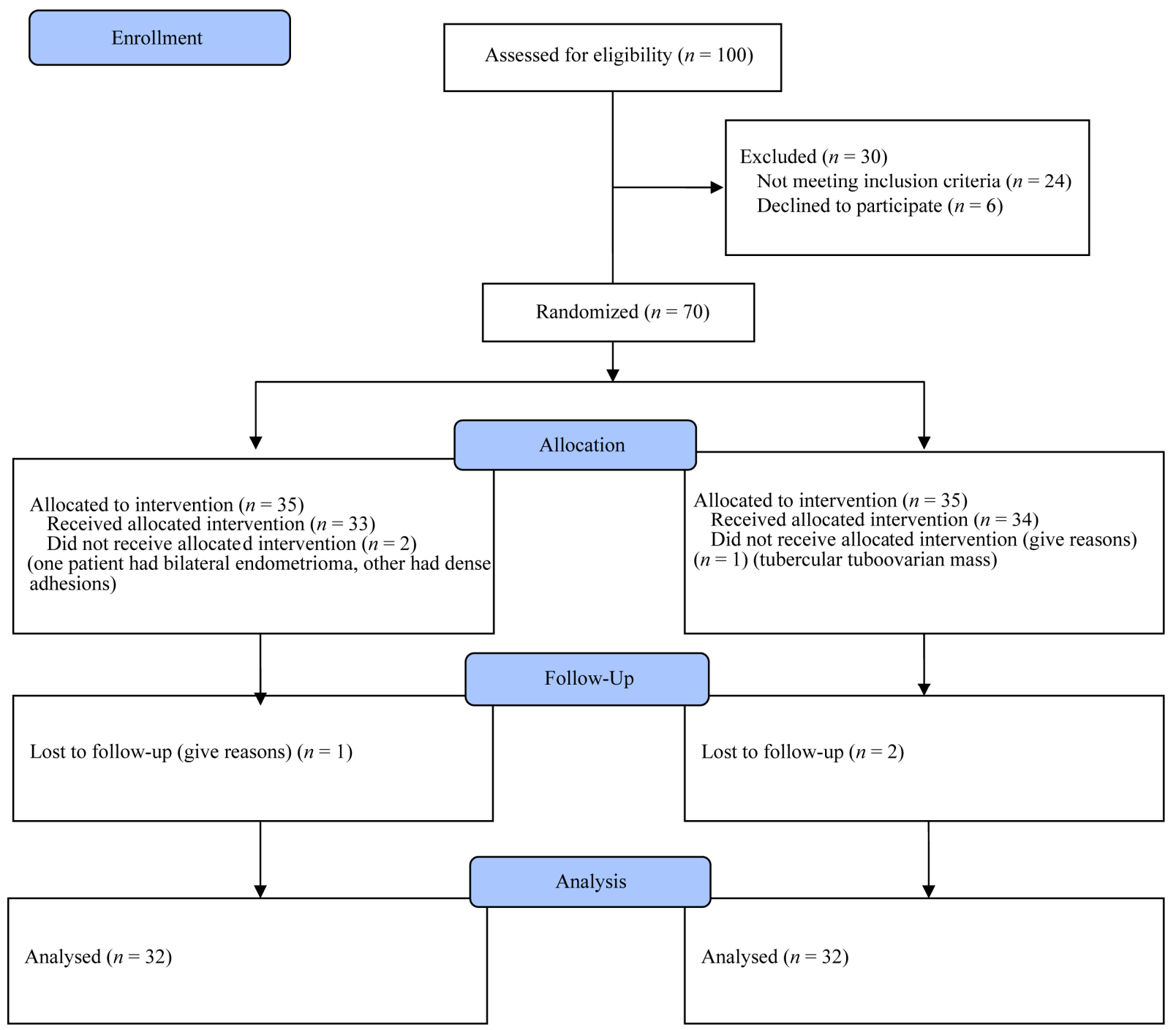

Figure 1. Flow of participants through the study. 
and blood loss during the procedure. Surgical difficulty was graded into three grades-easy, moderately difficult and difficult. Complications encountered during the procedure were recorded.

Excised endometriotic cyst was sent for histopathological examination. The final tissue at ovarian hilus was sent separately to obtain a quantitative analysis of normal ovarian tissue sa crificed in either technique during both the initial and final procedure.

The patients were discharged after 6 postoperative hours. The patients were followed up monthly, for six months by clinical examination and trans abdominal or trans-vaginal ultrasonography. Any conception that occurred during the follow up was recorded. Histopathologic confirmation of the loss of normal ovarian tissue was recorded. The data was computed, and a comparison of the two different surgical techniques was done.

Of 100 women assessed for eligibility, 70 women were enrolled into study. (Figure 1). Thirty five women were allocated into each group .Two women in group I and one woman in group II did not receive the allocated intervention as intraoperative findings did not meet the inclusion criteria. Thirty two women were finally included into analysis in each group. A formal sample size calculation had been done expecting average surgery time of 40 minutes for endometriotic cystectomy based on the experience with expected standard deviation of $10 \mathrm{~min}$ utes between cutting and stripping. To detect this difference with $90 \%$ power at the 0.05 alpha level, a sample size of 23 women was calculated in each group.

The randomization into two groups at both steps was done using a computer generated random number table. The randomization was revealed to the surgeon at the beginning of each step. The computed data was analyzed using the Stata software. The Student's t-test was used for continuous parametric variables and the chi squaretest was used for categorical variables. The Fisher's exact test was used to evaluate operative difficulty. The KruskalWallis test was used to evaluate the difference in quality of ovarian tissue removed at the three different cyst sites. Statistical significance was set at a $\mathrm{p}$ value less than 0.05 .

\section{Results}

The mean age of the patients studied was 27.2 years, with a range from 19 - 37 years. There were 4 patients $\leq$ 20 years of age and 2 patients $>35$ years. Twelve patients were unmarried, being investigated for dysmenorrhea. 52 were married of whom 42 patients were nulliparous, and 10 were parous. Two patients opted for tubal sterilization simultaneously. All recruited 64 patients had stage 3 or 4 disease as classified by the revised ASRM scoring system. There was no significant diffe- rence in baseline characterstics of patients enrolled in terms of age, body mass index (BMI) and cyst size between two groups. The mean score in both groups was 63, with scores ranging from 22 to 144 .

The baseline patient characteristics are summarized in Table 1. There was no significant difference between baseline characteristics of two randomized groups.

The primary data recorded during surgery was operative time and operative difficulty. Total operative time was recorded from induction of pneumoperitonem to final skin suture placement. Operative difficulty was judged by the chief surgeon and graded as easy, moderately difficult and difficult. There was significant difference in the operative time $(p<0.01)$ between two groups. The mean operative time was 8.8 minutes lesser in bipolar coagulation and cutting group (37.8 minutes in group I versus 29 minutes in group II). However, the operative difficulty was not significantly different $(p=0.9)$ between two groups. The surgical data with reference to difficulty encountered in surgery is summarized in Table 2.

At the end of surgery, the entire endometriotic cyst was submitted for histopathological examination. Hilar part of cyst wall was separated and submitted separately. Hilar region and remaining cyst wall were separately analysed by the pathologist for assessment of follicles. The mean tissue thickness was $0.82 \mathrm{~cm}$ in Group I and $0.98 \mathrm{~cm}$ in Group II. The quantitative and qualitative analysis of ovarian follicles is given in Table 3. No secondary follicles, or patterns similar to those present in the normal ovary could be identified.

Table 1. Baseline characterstics of the patients enrolled in the study.

\begin{tabular}{lcccc}
\hline \multicolumn{1}{c}{ Variables } & Overall & Group I & Group II & $P$ \\
\hline $\begin{array}{l}\text { Mean Age(years) } \\
\text { Mean Body Mass Index } \\
\left(\mathrm{Kg} / \mathrm{m}^{2}\right)\end{array}$ & 27.2 & 28.1 & 27.1 & $\mathrm{NS}$ \\
$\begin{array}{l}\text { Mean endometriotic cyst } \\
\text { size }( \pm \mathrm{SD})(\mathrm{cm})\end{array}$ & $4.6 \pm 1.4$ & 26.5 & 25.9 & $\mathrm{NS}$ \\
\hline
\end{tabular}

Table 2. Comparison of two techniques of endometriotic cystectomy: surgical data.

\begin{tabular}{lcccc}
\hline \multicolumn{1}{c}{ Variables } & Overall & Group I & $\begin{array}{c}\text { Group } \\
\text { II }\end{array}$ & $P$ \\
\hline $\begin{array}{l}\text { Total Laparoscopic time } \\
\text { (mean } \pm \text { SD) }\end{array}$ & $36.1 \mathrm{~mm}$ & $\begin{array}{c}37.8 \\
\text { min }\end{array}$ & $29 \mathrm{~min}$ & 0.8 \\
Surgical difficulty & & & & \\
Easy & 16 & 8 & 8 & \\
Moderately difficult & 22 & 10 & 12 & \\
Difficult & 26 & 14 & 12 & \\
\hline
\end{tabular}


Table 3. Histopathologic analysis for no. of follicles.

\begin{tabular}{ccccc}
\hline \multirow{2}{*}{$\begin{array}{c}\text { Grading of } \\
\text { Follicles }\end{array}$} & \multicolumn{2}{c}{$\begin{array}{c}\text { Endometriotic Cyst in } \\
\text { Hilar Area }\end{array}$} & \multicolumn{2}{c}{$\begin{array}{c}\text { Remaninder } \\
\text { Endometriotic Cyst }\end{array}$} \\
\cline { 2 - 5 } & $\begin{array}{c}\text { Group I } \\
(n=32)\end{array}$ & $\begin{array}{c}\text { Group II } \\
(n=32)\end{array}$ & $\begin{array}{c}\text { Group I } \\
(n=32)\end{array}$ & $\begin{array}{c}\text { Group II } \\
(n=32)\end{array}$ \\
No follicle & 26 & 26 & 29 & 28 \\
Primordial & 4 & 5 & 3 & 4 \\
Primary & 2 & 1 & 0 & 0 \\
\hline
\end{tabular}

The mean residual ovarian volume after six months ranged from $11.3 \mathrm{cc}$ to $11.5 \mathrm{cc}$. Using the $\mathrm{t}$ test, no significant difference was found in the residual ovarian volume between the two groups $(p=0.146)$. The pre op and post op residual ovarian volume was compared, and the mean difference ranged from 2.77 to $3.08 \mathrm{cc}$ in either group, which was not statistically significant.

A total of $6(18.75 \%)$ patients had a recurrence of endometrioma, in the follow up period of six months. On comparing the recurrence rates between two groups using Fisher's exact test, no significant difference was found with either technique used at the original adhesion site or at the hilus.

Of the 23 patients being investigated for infertility, there were $2(8.7 \%)$ conceptions. Both were spontaneous conceptions, one at four months follow up, in group 2 followed by stripping at the hilus. The second patient underwent stripping at the original adhesion site followed by coagulation and cutting. She conceived spontaneously in the fifth month.

There were no major complications encountered in either technique in any case. There were no postoperative complications. The mean blood loss was $86( \pm 12.1) \mathrm{cc}$ in Group I and $83.5( \pm 8.5) \mathrm{cc}$ in Group II, the difference being statistically non significant. Sixty two patients were discharged on the same postoperative day. In two patients, discharge was delayed till 24 hours till next postoperative day on patient demand.

\section{Discussion}

Ovarian endometrioma occurs in $17 \%$ - $44 \%$ of endometriosis and nearly $35 \%$ of benign ovarian cystic lesions are endometriomas [9]. Medical treatment of endometriomas remain to be inadequate and ultrasound-guided aspiaration is associated with high rate of recurrence and complications. Surgical removal of endometriotic cyst is associated with best clinical symptom relief and improved fecundity with lower recurrence rates. It has been proved in various studies the advantage of laparoscopic cystictomy over laparotomy [10].

Several laparoscopic techniques have been described for the treatment of ovarian endometriomata $>3 \mathrm{~cm}$, such as laser vaporization of the cyst wall [11-13], drainage and coagulation, and stripping $[7,14,15]$. The ideal laparoscopic conservative approach for endome- triomas is still controversial $[2,3,10]$.

A Hemmings et al. [16] demonstrated that cyst wall coagulation provoked less loss of ovarian tissue when compared to cystectomy. However Marconi et al. [17] demonstrated there was no reduction in ovarian reserve after laparoscopic ovarian cystectomy as determined by E2 levels, number of follicles, oocytes retrieved, number and quality of embryos transferred, and clinical pregnancy rate. Cochrane review by Hart et al. [5] showed that excisional surgery for endometriomata provides for a more favorable outcome than drainage and ablation, with regard to the recurrence of the endometrioma, recurrence of symptoms and subsequent spontaneous pregnancy in women who were previously sub fertile. Different techniques of laparoscopic ovarian cystectomy have been described though and subsequent fertility outcome, recurrence rates and ovarian function have been studied.

Although the stripping technique [18] is thought to be the technique of choice because it involves a more complete removal of the lesion, it is more traumatic and may reduce post operative ovarian reserve and function. Muzii et al. (2005) compared two different techniques of stripping at the beginning and at the hilar region [19] and concluded no significant difference in quality of ovarian tissue sacrificed or operative time with two different surgical techniques at the initial or at the final part of the procedure. Due to ease of operating with initial surgical technique of circular excision and subsequent stripping, authors adopted this technique with subsequent randomization at the hilus.

Hilar region of ovary has been recognized to have higher functional stages of follicular development in nearly $70 \%$ specimens, resembling normal pattern of primordial, primary and secondary follicles seen in healthy ovarian tissue [8]. Initial or intermediate parts of ovarian tissue are devoid of follicles or only scanty primordial follicles are recognized [8]. Hence in present study the two operative techniques of continuation of stripping and bipolar coagulation followed by cutting was analysed at hilar area.

Assessment of ovarian reserve and damage to the normal ovarian tissue after endometriotic cystectomy remains a challenge in literature. Despite the entity of the hypothetical injury related to the presence of the cyst, surgery undoubtedly leads to loss of normal ovarian tissue. However, which technique leads to minimal loss is still a question of debate. Excessive traction during stipping techniques may result in tearing of hilar vessels and 
removal of greater mean thickness of cyst wall and associated loss of follicles. Similarly non targeted coagulation may result in loss of ovarian cortex with adjoining inflammation, fibrosis and devasularisation. Apart from surgical technique, surgical skill may also affect loss of ovarian reserve as different thickness of cyst wall have been reported to be removed in different series. More tissue thickness is associated with greater loss of ovarian follicles [8]. Besides quantitative loss, some investigators have reported a reduction in oocyte quality, and thereby a decrease in fertilization rates [20]. It is suggested that ovarian endometriomas produce substances that are toxic to maturing oocytes and these substances may adversely affect cleavage of oocytes and fertilization. In the present study there was no significant difference between stripping procedure and coagulation plus cutting.

The time for surgery for endometriosis and ovarian cysts averages around $72 \mathrm{~min}$ (range 10 - 240) [21]. Laparoscopic management of endometriomas averaged 168 (SD 72) min and ranged between 20 and $150 \mathrm{~min}$ in two other series $[22,23]$. However, there are no studies in literature supporting one technique over another in terms of operative ease and operating time, given the short term and long term outcome in terms of symptomatic relief and ovarian reserve is same. In our study, the total operative time in group II comprised by coagulation and cutting was 29 minutes. This was significantly $(p<0.01)$ lesser than time taken by stripping procedure $(37.8 \mathrm{~min})$. To the best of our knowledge, this is first study comparing the operative time for surgeon's convenience in two equally effective techniques.

There were no major complications encountered in any of the patients recruited. There was no significant difference in blood loss between two procedures, however blood loss was slightly lesser in group II. The surgical difficulty encountered was also lesser in group II though there was no statistical difference. The cost of drugs in pain management postoperatively was comparable in both groups without any significant difference.

In conclusion, stripping of cyst is comparable with bipolar coagulation and cutting for endometriotic cystictomy in terms of patient's benefit and clinical outcome. However, Bipolar cutting and coagulation is often considered superior to continuation of stripping from surgeon's point of view. The present study is a significant contribution to literature to decide optimum technique for endometriotic cystectomy. Larger studies are needed to establish best surgical technique.

\section{REFERENCES}

[1] T. A. Mahmood and A. Templeton, "Prevalence and Genesis of Endometriosis," Human Reproduction, Vol. 6,
No. 4, 1991, pp. 544-549.

[2] P. Vercellini, C. Chapron, O. De Giorgi, D. Consonni, G. Frontino and P. G. Crosignani, "Coagulation or Excision of Ovarian Endometriomas?" American Journal of $\mathrm{Ob}$ stetrics and Gynecolog, Vol. 188, No. 3, 2003, pp. 606610. doi: $10.1067 / \mathrm{mob} .2003 .7$

[3] F. Golfier, M. Sabra, "Surgical Management of EndoMetriosis," Journal de Gynecologie, Obstetrique et Biologie de Lareproduction, Vol. 36, No. 2, 2007, pp. 162-172.

[4] P. Beretta, M. Franchi, F. Ghezzi, M. Busacca, E. Zupi and P. Bolis, "Randomized Clinical Trial of Two La- paroscopic Treatments of Endometriomas: Cystectomy Versus Drainage and Coagulation," Fertility and Sterility, Vol. 70, No. 6, 1998, pp. 1176-1180. doi:10.1016/S0015-0282(98)00385-9

[5] R. J. Hart, M. Hickey, P. Maouris, W. Buckett, "Excisional Surgery Versus Ablative Surgery for Ovarian Endometriomata," Cochrane Database of Systematic Reviews, Vol. 16, No. 2, 2008, Article No. CD004992.

[6] M. Busacca and M. Vignali, "Endometrioma Excision and Ovarian Reserve: A Dangerous Relation," Journal of Minimally Invasive Gynecology", Vol. 16, No.2, 2009, pp. 142-148. doi:10.1016/j.jmig.2008.12.013

[7] D. C. Martin, "Laparoscopic Treatment of Ovarian Endometriomas," Clinics in Obstetrics and Gynecology Vol. 34, No. 2, 1991, pp. 452-459. doi:10.1097/00003081-199106000-00029

[8] L. Muzii, F. Bellati, A. Bianchi, I. Palaia, N. Manci, M. A. Zullo, R. Angioli and P. B. Panici, "Laparoscopic Stripping of Endometriomas: A Randomized Trial on Different surgical Techniques. Part II: Pathological Results,' Human Reproduction, Vol. 20, No. 7, 2005, pp. 19871992. doi:10.1093/humrep/deh851

[9] P. Vercellini, "Endometriosis: What Pain It Is," Seminars in Reproductive Endocrinology, Vol. 15, No. 3, 1997, pp. 251-256. doi:10.1055/s-2008-1068755

[10] P. P. Yeung Jr, J. Shwayder and R. P. Pasic, "Laparoscopic Management of Endometriosis: Comprehensive Review of Best Evidence," Journal of Minimally Invasive Gynecology, Vol. 16, No. 3, 2009, pp. 269-281. doi:10.1016/i.jmig.2009.02.007

[11] I. A. Brosens, P. van Ballaer, P. Puttemans and J. Deprest, "Reconstruction of the Ovary Containing Large Endometriomas by an Extraovarian Endosurgical Technique," Fertility and Sterility, Vol. 66, No.4, 1996, pp. 517-521.

[12] J. Donnez, M. Nisolle, N. Gillet, M. Smets, S. Bassil and F. Casanas-Roux, "Large Ovarian Endometriomas," $\mathrm{Hu}$ man Reproduction, Vol. 11, No. 3, 1996, pp. 641-646.

[13] C. J. Sutton, S. P. Ewen, N. Whitelow and P. Haines, "Prospective, Randomized, Double-Blind Controlled Trial of Laser Laparoscopy in the Treatment of Pelvic Pain Associated with Minimal, Mild, and Moderate Endometriosis," Fertility and Sterility, Vol. 62, No. 4, 1994, pp. 696-700.

[14] M. Canis, G. Mage, A. Wattiez, C. Chapron, J. L. Pouly 
and S. Bassil, "Second Look Laparoscopy after Laparoscopic Cystectomy of Large Ovarian Endometriomas," Fertility and Sterility, Vol. 58, No. 3, 1992, pp. 611-619.

[15] H. Reich and F. McGlynn, "Treatment of Ovarian Endometriomas using Laparoscopic Surgical Techniques," Journal of Reproductive Medicine, Vol. 31, No. 7, 1986, pp. 577-584.

[16] R. Hemmings, F. Bissonnette and R. Bouzayen, "Results of Laparoscopic Treatments of Ovarian Endometriomas: Laparoscopic Ovarian Fenestration and Coagulation," Fertility and Sterility, Vol. 70, No. 3, 1998, pp. 527-529. doi:10.1016/S0015-0282(98)00219-2

[17] G. Marconi, M, Vilela, R. Quintana and C. Sueldo, "Laparoscopic Ovarian Cystectomy of Endometriomas Does Not Affect the Ovarian Response to Gonadotropin Stimulation," Fertility and Sterility, Vol. 78, No. 4, 2002, pp. 876-878. doi:10.1016/S0015-0282(02)03326-5

[18] K. Semm, "Course of Endoscopic Abdominal Surgery," Operative Manual for Endoscopic Abdominal Surgery, In: K. Semm and E. R. Freidrich, Eds., C.V. Mosby, Chicago, 1987, p. 21.

[19] L. Muzii, F. Bellati, I. Palaia, F. Plotti, N. Manci, M. A. Zullo, R. Angioli and P. B. Panici, "Laparoscopic Strip- ping of Endometriomas: A Randomized Trial on Different Surgical Techniques. Part I: Clinical Results," Human Reproduction, Vol. 20, No. 7, 2005, pp. 1981-1986. doi:10.1093/humrep/dei007

[20] E. H. Yanushpolsky, C. L. Best, K. V. Jackson, R. N. Clarke, R. L. Barbieri and M. D. Hornstein, "Effects of Endometriomata on Oocyte Quality, Embryo Quality, and Pregnancy Rates in in vitro Fertilization Cycles: A Prospective, Case-Controlled Study," Journal of Assisted Reproduction and Genetics, Vol. 15, No. 4, 1998, pp. 193-197. doi:10.1023/A:1023048318719

[21] A. Shushan, H. Mohamed and A. L. Magos, "How Long Does Laparoscopic Surgery Really Take? Lessons Learned from 1000 Operative Laparoscopies," Human Reproduction, Vol. 14, No. 1, 1999, pp. 39-43. doi:10.1093/humrep/14.1.39

[22] B. G. Bateman, L. A. Kolp, S. Mills, "Endoscopic Versus Laparotomy Management Ofendometriomas," Fertility and Sterility, Vol. 62, No. 4, 1994, pp. 690-695.

[23] P. Del, E. Girat and A. Vazquez, "Laparoscopic Management of Endometriosis with $\mathrm{CO}_{2}$ Laser," Gynaecology Endoscopy, Vol. 4, 1995, pp.195-199. 